\title{
Improving Mental Health Care for Returning Veterans
}

RAND RESEARCH AREAS

THE ARTS

CHILD POLICY

CIVIL JUSTICE

EDUCATION

ENERGY AND ENVIRONMENT

HEALTH AND HEALTH CARE

INTERNATIONAL AFFAIRS

NATIONAL SECURITY

POPULATION AND AGING

PUBLIC SAFETY

SCIENCE AND TECHNOLOGY

SUBSTANCE ABUSE

TERRORISM AND

HOMELAND SECURITY

TRANSPORTATION AND

INFRASTRUCTURE

WORKFORCE AND WORKPLACE

This fact sheet is part of the RAND Corporation research brief series. RAND fact sheets summarize published, peerreviewed documents.

Headquarters Campus

1776 Main Street

P.O. Box 2138

Santa Monica, California

90407-2138

TEL 310.393 .0411

FAX 310.393 .4818

(C) RAND 2009
A substantial number of the 1.7 million military servicemembers returning from the conflicts in Iraq and Afghanistan may face mental health problems. A comprehensive study conducted by RAND in 2008 found that an estimated 18.5 percent of those back from deployment reported symptoms consistent with a diagnosis of post-traumatic stress disorder (PTSD) or depression. The study also examined veterans' access to quality mental health treatment. It identified gaps in the military and veterans health care systems and opportunities for improvement. A large infusion of new funds into the Department of Defense (DoD) and the Veterans Health Administration (VHA) in recent years is supporting their continuing efforts to improve care. However, many returning veterans also seek care in community settings as they reintegrate into civilian life. As part of the Invisible Wounds of War project (http://www. rand.org/multi/military/veterans/), a RAND team published additional results identifying key challenges to the provision of mental health care that cut across community, VHA, and DoD health care settings.

The analysis identified two barriers to mental health care access in community settings:

- The mental health workforce has insufficient capacity. Mental health specialty care for conditions such as PTSD and depression is not readily available in many parts of the country. Most mental health specialists are concentrated in urban areas. Even where specialty care is available, limited health plan coverage may reduce access for veterans seeking care outside of the VHA.

- Military servicemembers and veterans are often reluctant to seek mental health care. Surveys uncovered widely held attitudes that can inhibit use of mental health services:

- Concern that admitting a mental health problem is a sign of weakness

- Fear that use of mental health services will have negative career repercussions (especially among active-duty personnel, who are required to disclose treatment)

- Skepticism about the effectiveness of treatment and concerns about the negative side effects of medication.

The analysis also found gaps in the quality of care in community settings. In particular, surveys suggested that in more than half of all cases, the treatment usually received did not meet recommended standards for care as supported by scientific evidence about what works. System-level challenges may limit the availability of evidence-based care in community settings:

- The mental health specialty workforce lacks sufficient training in evidence-based practices. Mental health providers in community settings may come from a variety of medical and mental health backgrounds. Theoretical orientations and standards of practice are diverse, with little cross-disciplinary standardization. In addition, the training of many specialists does not emphasize evidence-based treatments. Furthermore, many are unfamiliar with military culture or combat-related trauma and disorders.

- Organizational systems and tools that support quality improvement for mental health are not widely used. The DoD and civilian healthcare sectors, unlike the VHA, do not make extensive use of performance monitoring, feedback, and other organizational tools and models to improve mental health quality of care.

To address these issues, the researchers recommend a nationwide, coordinated effort to improve care by expanding the availability of training for treatment of combat-related mental disorders, promoting the development of organizational systems and tools to monitor performance and support quality improvement in mental health care, and providing technical assistance to states and communities that are working to address veterans' mental health needs.

This fact sheet is based on Burnam MA, Meredith LS, Tanielian T, and Jaycox LH, "Mental Health Care for Iraq and Afghanistan War Veterans," Health Affairs, Vol. 28, No. 3, May/June 2009, pp. 771-782. 
Office of Congressional Relations | 703-413-1100x5320 | ocr@rand.org | www.rand.org/congress

This fact sheet was written by David M. Adamson. The RAND Corporation is a nonprofit research organization providing objective analysis and effective solutions that address the challenges facing the public and private sectors around the world. RAND's publications do not necessarily reflect the opinions of its research clients and sponsors. RAND ${ }^{\circledR}$ is a registered trademark.

\section{RAND Offices}

Santa Monica, CA • Washington, DC • Pittsburgh, PA • New Orleans, LA/Jackson, MS • Boston, MA • Doha, QA • Cambridge, UK • Brussels, BE 
THE ARTS

CHILD POLICY

CIVIL JUSTICE

EDUCATION

ENERGY AND ENVIRONMENT

HEALTH AND HEALTH CARE

INTERNATIONAL AFFAIRS

NATIONAL SECURITY

POPULATION AND AGING

PUBLIC SAFETY

SCIENCE AND TECHNOLOGY

SUBSTANCE ABUSE

TERRORISM AND HOMELAND SECURITY

TRANSPORTATION AND INFRASTRUCTURE

WORKFORCE AND WORKPLACE
This PDF document was made available from www.rand.org as a public service of the RAND Corporation.

This product is part of the RAND Corporation research brief series. RAND research briefs present policy-oriented summaries of individual published, peerreviewed documents or of a body of published work.

The RAND Corporation is a nonprofit research organization providing objective analysis and effective solutions that address the challenges facing the public and private sectors around the world.

\section{Support RAND}

$\underline{\text { Browse Books \& Publications }}$

Make a charitable contribution

\section{For More Information}

Visit RAND at www.rand.org

Explore the RAND Center for Military Health Policy Research

View $\underline{\text { document details }}$

Limited Electronic Distribution Rights

This document and trademark(s) contained herein are protected by law as indicated in a notice appearing later in this work. This electronic representation of RAND intellectual property is provided for non-commercial use only. Unauthorized posting of RAND PDFs to a non-RAND Web site is prohibited. RAND PDFs are protected under copyright law. Permission is required from RAND to reproduce, or reuse in another form, any of our research documents for commercial use. For information on reprint and linking permissions, please see RAND Permissions. 